\title{
Age and Gender Based Self-Reported Impact of Disclosure of HIV/AIDS Diagnosis from Adolescents Receiving Care at University Teaching Hospital, Uyo, South-South Nigeria
}

\section{Dixon-Umo OT ${ }^{1 *}$,Ikpeme EE ${ }^{2}$ and Ekpenyong EE ${ }^{3}$}

${ }^{1}$ Senior Lecturer and Honorary Chief Consultant Paediatrician, Department of Paediatrics, University of Uyo/University of Uyo Teaching Hospital, Uyo, Nigeria ${ }^{2}$ Professor of Paediatrics and Honorary Chief Consultant Paediatrician, Department of Paediatrics, University of Uyo/University of Uyo Teaching Hospital, Uyo, Nigeria ${ }^{3}$ Fellow West African College of Physicians and Senior Registrar, Department of Paediatrics, University of Uyo Teaching Hospital, Uyo, Nigeria

*Corresponding Author: Dixon-Umo, OT. Senior Lecturer and Honorary Chief Consultant Paediatrician, Department of Paediatrics, University of Uyo/University of Uyo Teaching Hospital, Uyo, Nigeria.
Received: April 05, 2020

Published: June 15, 2020

(C) All rights are reserved by Dixon-Umo 0T., et al.

\section{Abstract}

Human immunodeficiency virus infection still contributes significantly to adolescent mortality in sub-Saharan Africa but many infected children are surviving into adolescence and adulthood. Infected adolescents need to know their status for their proper selfcare and prevention of transmission. Studies on effects of disclosure from adolescents' perspectives are few. This study sought for the self-reported impact on disclosed adolescents.

This was a descriptive cross-sectional hospital-based study of 52 adolescents (10-19 years) who knew their HIV infection status for over 6 months. A pretested questionnaire was used and it lasted between July 2019 and February 2020. The data obtained was analysed using statistical package for social sciences version 25.

Fifty-eight of 140 adolescents aged 10-19years knew their HIV diagnosis (disclosure rate $=41.4 \%$ ) and 52 assented with caregivers' consent to participate. Mean age of participants was $15.1 \pm 2.2$ years with 21 males and 31 female giving male: female ration of 1:1.4. Age-related significant findings were third party disclosure $(\mathrm{P}=0.002)$, membership of support group and attending clinics unaccompanied ( $\mathrm{P}=0.009$ and 0.007 respectively). Gender-based responses were 3rd party disclosure and attending clinic unaccompanied ( $\mathrm{P}=0.01$ and 0.02 respectively). Adherence improved following disclosure and majority preferred being disclosed to and were hopeful in their outlook to life, but these were not significant in relations to their ages or gender. In conclusion, older disclosed adolescents are able to access care for themselves and benefit from peer psychosocial support. Keywords: Adolescent; Disclosure; HIV Diagnosis; Self-Report; Impact

\section{Introduction}

Adolescents' disclosure of HIV diagnosis and the impact on them is a crucial investment and age-specific focus towards the goal of ending the adolescent AIDS epidemic by 2030. About 1.6 million adolescents (10-19 years) are living with HIV worldwide and they are the only group with a non-decreasing AIDS-related mortality [1]. As much as 1.5 million (89\%) of these adolescents live in sub-
Saharan Africa. Nigeria remains the second largest epidemic in the world after South Africa [1]. In 2017, adolescents contributed 7\% to the HIV infected population of Nigeria and the prevalence of adolescent HIV infection differed between the geopolitical zones, with $4.3 \%$ in the south-south compared to $1.3 \%$ in south-east [2]. The health outcome for HIV infected adolescents in Nigeria is poor and this is the only country where 10-14 years old record a rising AIDS related mortality [2]. 
The complexities of disclosing the HIV diagnosis to infected children and adolescents make their care-givers to shroud the lives of these young clients in secrecy of their infection status. At adolescence, infected clients ultimately become aware of their health challenges, and may question routine medications and frequent clinic visits $[3,4]$. Therefore, they will either be eventually disclosed to or may discover their infection status themselves with attendant reactions, especially at the initial period. Eventual disclosure by parents and other caregivers or the permission for disclosure to be made, is related to the assessment of the adolescent's ability to handle the information and cope with the possibility of the stigma that is associated with HIV infection. Consequently parents, caregivers and sometimes healthcare workers decide to withhold disclosure till when the child is assessed to have achieved the developmental capability of handling this confidential information [5-10]. A study from Uyo, Nigeria, showed that $45 \%$ of parents and caregivers chose 15 years of age as appropriate for disclosure and that only $16.4 \%$ of HIV-infected children aged 9-17 years have been disclosed to [5].

Some studies on the impact of HIV diagnosis disclosure to infected children/adolescents have shown positive outcomes, especially improved adherence to ART which is the mainstay of halting disease progression [11-14]. As high as 100\% response rate of improvement in adherence was reported by Peterson [14], though the range is variable. Factors which improve adherence to HAART are invaluable since over $95 \%$ adherence is required for avoidance of drug resistance and consequent treatment failure [15]. However, a contrasting result from Vreeman., et al. [16] showed that the disclosed children reported more non-adherence than non-disclosed children. Other reported impact including self-esteem [17], emotional and psychological changes [18] as well as prevention of transmission $[19,20]$ have been variably different in disclosed compared to non-disclosed children and adolescents. DusabeRichards., et al.[21] observed the advantages of disclosure of HIVinfection status to infected children to include taking control of their healthcare, visiting health facilities unaccompanied, good adherence to their antiretroviral medications and better communication about their health issues. Also, Mburu., et al.[22] in a study of Zambian adolescents aged 10-19 years reported that some adolescents described being anxious, depressed and also regretted being disclosed to, but admitted that disclosure afforded them the opportunity of accessing adherence and other psychosocial support from family and peers [22].
Studies on impact of disclosure in adolescents from resource limited settings are relatively few in view of the bulk of adolescent HIV infection occurring in sub-Saharan Africa [1].Also, there are increasing reports of infected children surviving into adolescence and adulthood due to diligent utilisation of the free antiretroviral therapy [23-25].Vreeman., et al.[26] had documented on the perceived impact by parents and caregivers of disclosure of HIV diagnosis to infected children in a resource limited setting of western Kenya. Few studies have been carried out on disclosure of HIV diagnosis from the perspective of children/adolescents who have been disclosed to $[20,21,27]$.

This study set out to assess the post disclosure outcomes from adolescents living with HIV/AIDS in a high prevalent resource-limited setting, with regards to their own reactions to disclosure, any effects on their emotional and psychological well being and whether or not there were age or gender differences. It also sought to know whether or not their preference is for disclosure. It is hoped that the responses from these clients will add to the literature on this important health concern.

\section{Methods}

This was a descriptive cross-sectional study at the paediatric infectious diseases clinic of the University of Uyo Teaching Hospital (UUTH), Uyo, Nigeria from July 2019 to February 2020. A pretested semi-structured questionnaire was administered to assenting adolescents living with HIV/AIDS whose parents or guardians have signed informed consent for their inclusion in the study. Only the adolescents, who have had their HIV infection status disclosed to them in no uncertain terms, and for at least six months, were recruited. Clients were recruited in a consecutive order during their regular clinic visits on Wednesday mornings or during their adolescent support group meetings which holds once in the afternoon of every third Saturday of the month. The confidentiality of respondents was ensured as no personal identities were used. They were informed of the voluntary nature of their participation in the study and that declining participation will not affect the standard care that is required at the health facility.

The questionnaire had 50 items including their bio data, level of education if in school, their parents or guardians' educational attainment and their occupations. The social class of each adolescent was determined using Oyedeji's[28] classification which is derived by adding each of parents/caregivers' educational points to the oc- 
Age and Gender Based Self-Reported Impact of Disclosure of HIV/AIDS Diagnosis from Adolescents Receiving Care at University Teaching Hospital, Uyo, South-South Nigeria

cupation points and dividing by four with the result corrected to the nearest whole number. The points for education and occupation of parents/caregivers are scaled I to $\mathrm{V}$ with the highest level of education being I (university degree and above) and the lowest being $\mathrm{V}$ (no formal education or can just read and write); while occupation is also I to $\mathrm{V}$ with I being the highest paid (senior civil servants, chief executive officers or equivalent) and $V$ being the unemployed, students or full time housewives [28]. Other items included questions on: who disclosed to them?, what was their initial reaction to disclosure?, what do they now think about being disclosed to?, who is their treatment partner, whether or not they attend clinics on their own?, if they had missed clinic appointment?, whether or not they are members of adolescent HIV support group and attend meetings?, whether they prefer being disclosed to or regret the disclosure, whether or not they have disclosed their status to anyone else, their perceived reactions from those they disclosed to.Questions were also asked about their sexuality, their hopes (outlook to life), whether or not they ever consider that life is not worth living, any challenges with taking their routine medications, whether or not they have achieved viral suppression, and if they have been hospitalized in past 6 months?

The average duration of completion of the questionnaire was 20 minutes. The questionnaires were either self-administered (for older adolescents) or administered by the researchers while clients were waiting to see the doctor on clinic days and during the "adolescent support group meetings".The clients were asked to clarify any uncertainties and their answers were cross-checked after completion.

The responses were entered into statistical package for social sciences (SPSS) version 25. Simple frequencies were calculated and cross tabulations done to describe the statistics. Significant values were taken as Pearson Chi-square, $P=0.05$.

\section{Results}

A total of 204 children aged 0-18 years are on follow-up in the paediatric ART unit comprising 64 (31.4\%) of less than 10 years and $140(68.6 \%)$ of $10-18$ years old. Out of the 140 clients aged 1018 years, 58 (41.4\%) have had a full disclosure of their HIV/AIDS diagnosis. Of these 58 clients, six declined, three of them learnt of their status by checking the names of medications on goggle search engine. Fifty-two participated in the study, comprising of 21 males (40.4\%) and 31 females (59.6\%) with a male to female ratio of $1: 1.48$. The mean age of participants was $15.1 \pm 2.2$ years.
The most predominant social class was social class III, 15 (28.8\%) which is like the middle class; while the lowest class was the least represented (7.7\%). Majority of the clients had both parents alive 28 (53.8\%) but $46.2 \%$ had lost either or both parents. The bulk of respondents were in secondary schools; 24 (46.2\%) in senior secondary while $13(25.0 \%)$ were in junior secondary level. Six $(11.5 \%)$ of the clients were out of school and smallest group were $3(5.8 \%)$ in primary school. These frequencies of the socio-demographic factors of participants are shown in table 1.

\begin{tabular}{|c|c|c|}
\hline Characteristics & Frequency & Percentage \\
\hline \multicolumn{3}{|l|}{ Gender } \\
\hline Male & 21 & 40.4 \\
\hline Female & 31 & 59.6 \\
\hline \multicolumn{3}{|l|}{ Age (years) } \\
\hline $10-12$ & 8 & 15.4 \\
\hline $13-15$ & 20 & 28.5 \\
\hline $16-18$ & 24 & 46.1 \\
\hline \multicolumn{3}{|l|}{ Social class } \\
\hline I & 12 & 23.1 \\
\hline II & 8 & 15.4 \\
\hline III & 15 & 28.8 \\
\hline IV & 13 & 25.0 \\
\hline $\mathrm{V}$ & 4 & 7.7 \\
\hline \multicolumn{3}{|l|}{ Parentage } \\
\hline Father only & 11 & 21.2 \\
\hline Mother only & 6 & 11.5 \\
\hline Both parents alive & 28 & 53.8 \\
\hline Complete orphan & 7 & 13.5 \\
\hline \multicolumn{3}{|l|}{ Level of education } \\
\hline Primary school & 3 & 5.8 \\
\hline Junior secondary school & 13 & 25.0 \\
\hline Senior secondary school & 24 & 46.2 \\
\hline Post secondary school & 6 & 11.5 \\
\hline Not in school & 6 & 11.5 \\
\hline Total & 52 & 100.0 \\
\hline
\end{tabular}

Table 1: Socio-demographic parameters of participants.

Table 2 shows the responses of participants with relation to their ages. Most of the disclosures were done by parents with mothers 23 (44.2\%) disclosing more than fathers 16 (30.8\%) while the least disclosure was one case by the nurses, but there was no sta- 
Age and Gender Based Self-Reported Impact of Disclosure of HIV/AIDS Diagnosis from Adolescents Receiving Care at University Teaching Hospital, Uyo, South-South Nigeria

tistical significance $(\mathrm{P}=0.52)$. There was no statistical relationship between age and the reaction to disclosure though the commonest reaction to disclosure was being sad 24 (46.2\%) and was commoner with older respondents; the younger children had mild or no reactions $(\mathrm{P}=0.73)$. Fifty $(96.2 \%)$ preferred that their status was disclosed to them while $3.8 \%$ regretted being told but this was not statistically significant $(\mathrm{P}=0.82)$. Four $(7.7 \%)$ of the clients who knew their status had disclosed to someone else and the younger age group were significantly more likely to disclose their status ( $P$ $=0.002)$. Though $47(90.4 \%)$ said their adherence to HAART was better and the older the age the higher the response, there was no statistical significance of this relationship. The older clients had a more positive outlook of being hopeful compared to the younger age group, it was not a statistically significant relationship $(\mathrm{P}=$ 0.22). The older clients were more likely to join the support groups as well as coming to clinics alone and both of these relationships were statistically significant, $\mathrm{P}=0.009$ and $\mathrm{P}=0.007$ respectively. That older clients were more likely to be sexually active, achieve viral suppression, or miss clinic appointments were not significant. $(\mathrm{P}=0.30 ; \mathrm{P}=0.52$; and 0.11 respectively).

\begin{tabular}{|c|c|c|c|c|c|c|c|c|c|c|}
\hline Age (years) & & \multirow{2}{*}{$10-12$} & \multirow{2}{*}{$\%$} & \multirow{2}{*}{ 13-15 } & \multirow{2}{*}{$\%$} & \multirow{2}{*}{$16-18$} & \multirow{2}{*}{$\%$} & \multirow{2}{*}{ Total } & \multirow{2}{*}{$\%$} & \multirow{2}{*}{ P-value } \\
\hline Responses & & & & & & & & & & \\
\hline \multirow[t]{4}{*}{ Who disclosed } & Father & 3 & 5.8 & 4 & 7.7 & 8 & 15.4 & 15 & 28.9 & 0.52 \\
\hline & Mother & 1 & 1.9 & 10 & 19.2 & 11 & 21.1 & 22 & 42.3 & \\
\hline & Relatives & 2 & 3.8 & 3 & 5.8 & 2 & 3.8 & 7 & 13.4 & \\
\hline & Doctors & 2 & 3.8 & 3 & 5.8 & 3 & 5.8 & 8 & 15.4 & \\
\hline \multirow[t]{7}{*}{ Reactions } & Sad & 2 & 3.8 & 11 & 21.1 & 11 & 21.1 & 24 & 46,2 & 0.73 \\
\hline & Shocked & 2 & 3.8 & 2 & 3.8 & 3 & 5.8 & 7 & 13.5 & \\
\hline & Angry & 0 & 0.0 & 1 & 1.9 & 1 & 1.9 & 2 & 3.8 & \\
\hline & None & 2 & 3.8 & 4 & 7.7 & 4 & 7.7 & 10 & 19.2 & \\
\hline & Depressed & 0 & 0.0 & 0 & 0.0 & 2 & 3.8 & 2 & 3.8 & \\
\hline & Scared & 1 & $1-9$ & 1 & 1.9 & 2 & 3.8 & 4 & 7.7 & \\
\hline & Relieved & 1 & 1.9 & 1 & 1.9 & 1 & 1.9 & 3 & 5.8 & \\
\hline \multirow[t]{2}{*}{ Prefer disclosure } & Yes & 8 & 15.4 & 20 & 38.5 & 22 & 42.3 & 50 & 96.2 & 0.82 \\
\hline & No & 0 & 0.0 & 0 & 0.0 & 2 & 3.8 & 2 & 3.8 & $0.002^{*}$ \\
\hline \multirow{2}{*}{$\begin{array}{l}\text { Any third-party dis- } \\
\text { closure }\end{array}$} & Yes & 3 & 5.8 & 0 & 0.0 & 1 & 1.9 & 4 & 7.7 & \\
\hline & No & 5 & 9.6 & 20 & 38.5 & 23 & 44.2 & 48 & 92.3 & 0.20 \\
\hline \multirow[t]{3}{*}{ Life's outlook } & Hopeful & 7 & 13.5 & 19 & 36.5 & 21 & 40.4 & 47 & 90.4 & \\
\hline & No hope & 0 & 0.0 & 1 & 1.9 & 1 & 1.9 & 2 & 3.8 & \\
\hline & Declined & 1 & 1.9 & 0 & 0.0 & 2 & 3.8 & 3 & 5.8 & \\
\hline \multirow[t]{2}{*}{ Adherence to HAART } & Better & 5 & 9.6 & 20 & 38.5 & 23 & 44.2 & 48 & 92.3 & \\
\hline & No change & 3 & 3.8 & 0 & 0.00 & 1 & 1.9 & 4 & 7.7 & \\
\hline \multirow{2}{*}{$\begin{array}{l}\text { Support group } \\
\text { member }\end{array}$} & Yes & 0 & 0.0 & 9 & 17.3 & 15 & 28.9 & 24 & 46.2 & 0.009* \\
\hline & No & 8 & 15.4 & 11 & 21.1 & 9 & 17.3 & 28 & 53.8 & \\
\hline \multirow[t]{3}{*}{ Attend clinic alone } & Always & 1 & 1.9 & 8 & 15.4 & 17 & 32.7 & 26 & 50.0 & 0.007* \\
\hline & Sometimes & 0 & 0.0 & 3 & 5.8 & 4 & 7.7 & 7 & 13.5 & \\
\hline & Not at all & 7 & 13.5 & 9 & 17.3 & 3 & 5.8 & 19 & 36.5 & \\
\hline \multirow[t]{2}{*}{ Missed appointment } & Yes & 2 & 3.8 & 2 & 3.8 & 9 & 17.3 & 13 & 25.0 & 0.11 \\
\hline & No & 6 & 11.5 & 18 & 34.6 & 15 & 28.8 & 39 & 75.0 & \\
\hline \multirow[t]{2}{*}{ Viral suppression } & Yes & 5 & 9.6 & 17 & 32.7 & 19 & 36.5 & 41 & 78.8 & 0.52 \\
\hline & No & 3 & 5.8 & 3 & 3.8 & 5 & 9.6 & 11 & 21.2 & \\
\hline \multirow[t]{3}{*}{ Sexually active } & Yes & 0 & 0.0 & 0 & 0.0 & 2 & 3.8 & 2 & 3.8 & 0.30 \\
\hline & No & 8 & 15.4 & 20 & 38.4 & 22 & 42.3 & 50 & 96.2 & \\
\hline & Total & 8 & 15.4 & 20 & 38.4 & 24 & 46.1 & 52 & 100.0 & \\
\hline
\end{tabular}

Table 2: Responses of participants with relation to their ages. *: Significant P-value. 
Age and Gender Based Self-Reported Impact of Disclosure of HIV/AIDS Diagnosis from Adolescents Receiving Care at University Teaching Hospital, Uyo, South-South Nigeria

Table 3 shows that in terms of relationships of gender and responses, the statistically significant responses were: females being more likely to attend clinic alone while the males were more likely to disclose their status to someone else, $\mathrm{P}=0.02$ and $\mathrm{P}=0.01$ respectively. Though the females were more in their preference for disclosure, hopeful outlook to life and of greater membership in support groups these were not statistically significant. Also, there was no statistical significance of the female being sexually active, achieving viral suppression and missing clinic appointments. No adolescent was hospitalised during the period of study.

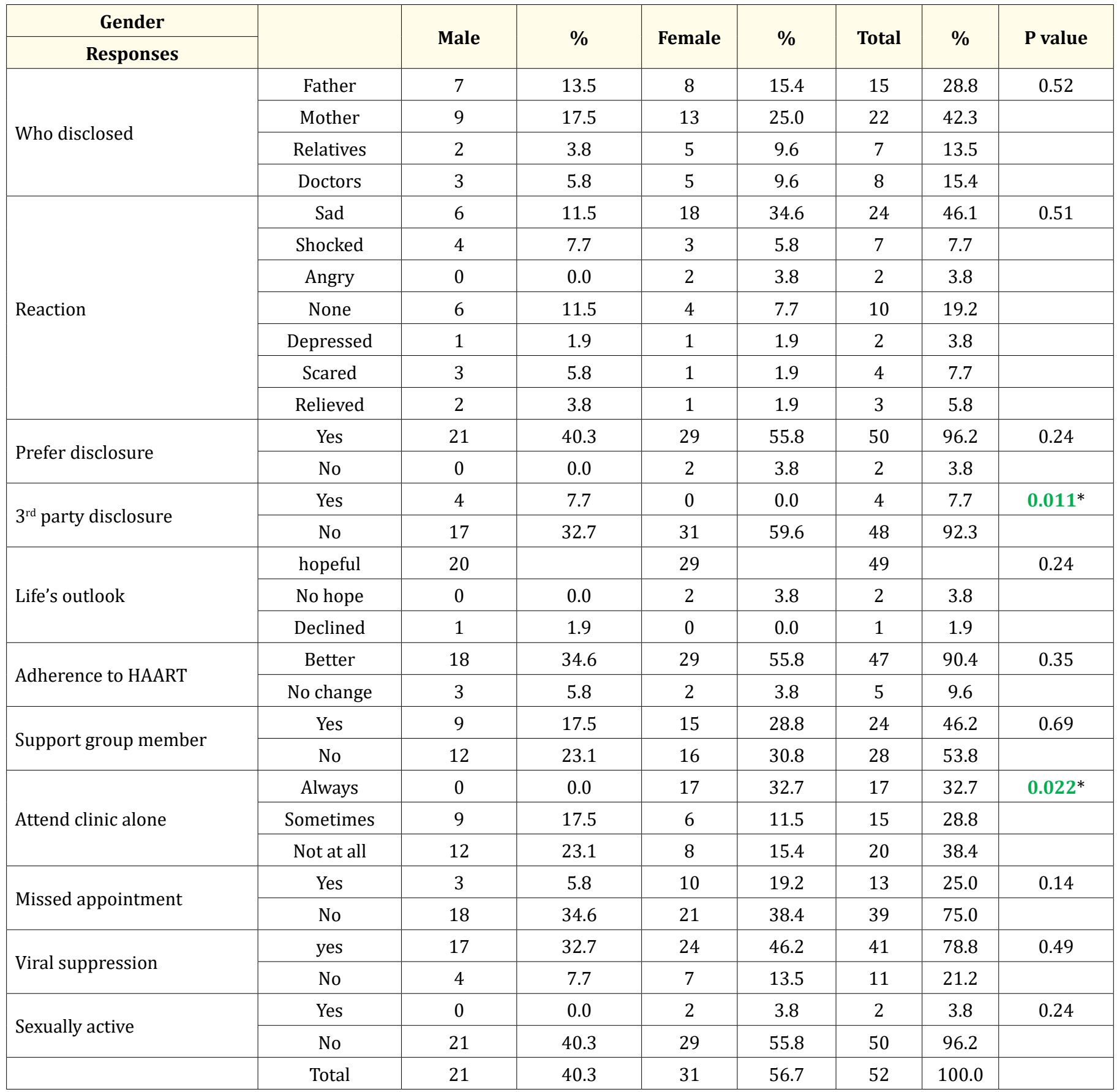

Table 3: Gender-based post disclosure responses. * = Significant P-value 


\section{Discussion}

This study shows a relatively higher disclosure rate of $41.4 \%$ compared to previous $16.4 \%$ at the same centre in 2016 [5] and previous national paediatric HIV/AIDS disclosure rates of between $13.5 \%$ to $30.9 \%$ [5-7]. This is comparable to $42.0 \%$, reported by Cohen.,et al.[29]from United States of America which is resource rich setting but still lower than the 95\% reported from that study in children aged 10 years and above [29].

The gender distribution of our study population showed a higher prevalence of female adolescents who know their HIV diagnosis. In 2018, the update report showed that adolescent females in sub-Saharan countries were two to three times more likely to be infected with HIV in comparison to boys of the same age group [1].

Majority of our subjects were aged 16-18 years and this is logical since age is a key consideration in disclosure of childhood/adolescent HIV infection. The older and more mature the child is, the greater the confidence that confidentiality of diagnosis of infection status can be maintained. Some studies have shown that 15 years and above is a more acceptable age for parents and caregivers to disclose HIV infection status to infected children [3-10].

The social classes III and IV were the highest representation and this may reflect the predominance of the lower socio-economic class from a resource-limited country like the study setting [28].

Adolescents with both parents alive were more than the orphans but as much as $13.5 \%$ of the study population were complete orphans and large numbers of AIDS orphans is commonplace in Nigeria. In 2017, an estimated 1.8 million Nigerian children were orphaned by AIDS [2].

Most of the respondents were in secondary school (25\% in junior secondary and $46.2 \%$ in senior secondary) which is slightly higher than $64.1 \%$ reported by Eneh.,et al.[27], though their study had younger children of 8 years old.Also $11.5 \%$ were out of school which is not unusual considering the associated socio-economic challenges of the HIV scourge in Nigeria[30].

The age-related responses showed a significant association between age and third party disclosure as the younger adolescents were more likely to disclose their infection status to others. This is in keeping with the parents'/caregivers' decision to defer disclosure for fear of inadvertent disclosure to third parties by children who are too young to keep confidential information [4-6]. Inadver- tent disclosure is a major fear for mothers who cannot risk the potential stigma associated with simultaneous disclosure of maternal HIV status because of disclosure of child's diagnosis [6].Conversely, Mburu., et al.reported more of third party disclosure in older adolescents who disclosed their status to their sexual partners [22].

The older adolescents were significantly more likely to attend clinic unaccompanied as well as being members of the adolescent HIV support group, $P=0.007$ and $P=0.009$ respectively. This trend is expected since the older adolescent is relatively more mature and can have more independence and autonomy than the younger ones. In a systematic review of disclosure of HIV status to children in subSaharan Africa, it was reported by Dusabe-Richards., et al.[21] that the merits of adolescent disclosure include their being able to take charge of their health and be able to visit the health facility on their own [21].Mburu., et al.reporting on the outcome of a qualitative study of 58 adolescents (10-19 years old) who had HIV disclosure, noted that they accessed peer psychosocial support better [22].

Other age-related reports, though not statistically significant, showed that the parents, especially mothers, followed by fathers, were more likely to disclose the HIV infection status to their children. This has also been documented from previous studies [6,27]. Eneh., et al.[27] corroborated that $38,8 \%$ of disclosure was done by mothers while fathers disclosed in $7.7 \%$ of cases.

The highest response to initial reactions to disclosure, though not statistically significant, was among the older adolescents who were more likely to be sad, depressed, or confused etc. compared to the younger adolescents. Nevertheless, the oldest age group were the highest responders that they have a positive and hopeful outlook to life, which presupposes that they have got over the initial negative reactions. Literature confirming more negative reactions in older adolescents compared to early adolescents could not be located. However, this finding may suggest that the older adolescents may be more mature and more knowledgeable about the challenges of living with HIV and therefore had more negative reactions. Moreover, Namukwaya., et al.[3] reported that contrary to caregivers' fears, $82.1 \%$ disclosed children overcame their immediate negative reactions and understood why they needed to continue on their medications. Also, in an interventional evaluation study, Blasini., et al.found that up to $70 \%$ of youth reported normalcy 6 months post disclosure [31]. Those who reported still being depressed and helpless are receiving psychotherapeutic counselling with good response. 
There was also no statistical significance in the preference to disclosure or their outlook to life even though $92.2 \%$ of them were in favour of accepting disclosure and majority said they were hopeful. More of the older adolescents had come to terms with their diagnosis and admitted that they no longer have negative reactions but two still felt hopeless about life and regretted being made aware of their HIV diagnosis. Our findings corroborate with findings from Blasini., et al.where $90 \%$ of disclosed children favoured disclosure and $85 \%$ felt that it was a positive event [31].

The variations of reaction to disclosure is however wide and they have been reports of psychiatric admissions in American children above 13 years of age due to post disclosure depression [32]. The authors however did not indicate how these compared with depression rates in the general American adolescent population or compared to non-disclosed HIV infected adolescents.

The majority of our clients (90.4\%) admitted to improved adherence after disclosure and the improvement was higher with older adolescents though this was not statistically significant. Selfreported adherence improvement of $100 \%$ among 78 adolescents who knew their HIV status had also been documented by Eneh.,et al.[27], though it was not related to age. In contrast, Vreeman., et al.[16], documented that disclosed children reported more non-adherence than non-disclosed children. Concerning sexuality, though the older adolescents were expectedly more likely to be sexually active, this was not of any statistical significance and only two females were sexually active. A self-reported sexual activity among disclosed adolescents was also documented by Eneh.,et al.where two out of 78 adolescents reported transmission of HIV infection through sexual activity [3]. Mburu.,et al.[22] reported that some Zambian adolescents, aged 10-19 years were not only sexually active but 6 were actually married with children. This highlights the importance of early disclosure to prevent HIV transmission from infected adolescents to their sexual partners or to their babies in case of adolescent females.

Our study also showed that the older adolescents were more likely to achieve viral suppression, though this was not a statistically significant finding. The reported viral suppression rate is however still below the expected 95\%. Literature of self report of adolescents' viral suppression was not available for comparison. Also, our older adolescents were more likely to miss clinic but again this was not statistically significant. Though they are no literatures on these findings of adolescent viral suppression and missing clinic, it may not be unconnected with their greater independence as some of them are beginning to take charge of their treatment and arrange for medication pick-up during adolescent support group meetings in the hospital and only call to say that the clinic visit does not favour them. This trend may not have been if they did not know their diagnosis.

The gender-based responses showed that females were more likely to attend clinic alone and this was statistically significant, $\mathrm{P}$ $=0.02$. Previous literature on the benefits of disclosure had shown that adolescents who know their status were more likely to attend clinic unaccompanied [21] but we did not locate literature that showed that girls were more likely to attend clinic alone. This may reflect our culture of giving girls more responsibilities and at an earlier age.

Another statistically significant finding was that all the disclosure to others were done by the males and while there are no findings in the literature to compare with this, the authors think this may be because the bulk of males who disclosed were younger and may not have the behavioural maturity to keep confidentiality.

The females were more in the preference of disclosure, more in their positive outlook to life, had a larger membership of the HIV adolescent support group, were also more likely to miss appointment and were more likely to achieve viral suppression but these were not statistically significant and there are no previous reports for comparison.

Considering sexual activity, the two adolescents who reported that they were sexually active were females. Though this was also not statistically significant a Nigerian study in the general population had shown that the median survival time of sexual debut was 19 years and females were twice as likely to begin sexual activities than their male counterparts, $\mathrm{HR}=1.99,1.87-2.11$ [33].

\section{Conclusion}

The disclosed adolescents in this study did not have significant negative emotional and behavioural traits, from their self-reported responses; they still have a positive outlook to life and prefer that the disclosure was made to them. Older adolescent girls were significantly more likely to take charge of their treatment by attending clinic unaccompanied and being members of the adolescent support group while younger adolescent boys were more likely to disclose their status to others. 


\section{Recommendation}

More parents should be encouraged to disclose to their infected adolescents as their responses did not show that they are at serious disadvantage of post disclosure outcomes. Primary caregivers of children infected with HIV should be empowered to disclose their diagnosis to them so that they can take charge or cooperate for a better treatment outcome.

\section{Limitation}

This study was mostly based on a recall of 6 months or more and this might have affected the responses obtained.

\section{Acknowledgement}

The authors are grateful to the parents and other caregivers who gave consent for this study and the adolescents for their assent in participating. We also acknowledge with gratitude the clerical assistance of the case manager, Ms Blessing Edet.

\section{Bibliography}

1. Global HIV and AIDS statistics-2019 fact sheet (2020).

2. National Bureau of statistics (NBS) and United Nation's Children Fund (UNICEF). “Multiple Indicator Cluster Survey 20162017". Survey Findings Report(2017).

3. Namukwaya S., et al. "How Do We Start? And How Will They React?"Disclosing to Young People with Perinatally Acquired HIV in Uganda". Frontiers in Public Health 5 (2017): 343.

4. John-Stewart GC., et al. "Prevalence, perceptions and correlates of pediatric HIV disclosure in an HIV treatment programme in Kenya". AIDS Care25 (2013): 1067-1076.

5. Ikpeme E and Dixon-UmoOT."Disclosure of HIV diagnosis to infected children receiving care in University of Uyo Teaching Hospital, Uyo, Nigeria". JAHR8 (2016): 93-99.

6. Brown BJ., et al. "Disclosure of HIV status to infected children in a Nigerian HIV Care Programme". AIDS Care 23 (2011): 1053-1058.

7. Odiachi A and Abegunde D. "Prevalence and predictors of paediatric disclosure among HIV-infected Nigerian Children on treatment". AIDS Care 28 (2016): 1046-1051.

8. Gerson AC., et al. "Disclosure of HIV diagnosis to children: when, where, why and how". The Journal of Pediatric Health Care 15 (2001): 161-167.
9. AlemuA., et al. "Challenges of Caregivers to Disclose Their Children's HIV Positive Status Receiving Highly Active Antiretroviral Therapy at Pediatric Antiretroviral Therapy Clinic in Bahir Dar, North West Ethiopia". Journal of AIDS and Clinical Research 4 (2013): 253.

10. Gyamfi E., et al. "Prevalence of, and barriers to the disclosure if HIV status to infected children and adolescents in a district of Ghana". BMC International Health and Human Rights 17 (2017): 8.

11. Brackis-Cott E., et al. "Paediatric HIV medication adherence: The views of medical providers from two primary care programs". Journal of Pediatric Health Care 17 (2003): 252-260.

12. Marhefka SL., et al. "Caregivers' psychosocial characteristics and children's adherence to antiretroviral therapy". AIDS Care STDs 20 (2006): 429-437.

13. Ferris M., et al. "The influence of disclosure of HIV diagnosis on time to disease progression in a cohort of Romanian children and teens". AIDS Care 19 (2007):1088-1094.

14. Peterson I., et al. "Psychosocial challenges and protective influences for socio-emotional coping of HIV+ adolescents in South Africa: a qualitative investigation". AIDS Care 22 (2010): 970978.

15. Federal Ministry of Health. "National Guidelines for HIV and AIDS Treatment and Care in Adolescents and Adults". Abuja, Nigeria: Federal Ministry of Health (2010).

16. Vreeman RC., et al. "A cross-sectional study of disclosure of HIV status to children and adolescents in western Kenya". PLoS One 9 (2014):e86616.

17. American academy of paediatrics. "Committee on Pediatric AIDS. Disclosure of illness status to children and adolescents with HIV infection". Paediatrics 103.1 (1999): 164-166.

18. Midtbø V., et al. "How disclosure and antiretroviral therapy help HIV infected adolescents in sub-Saharan Africa”. African Journal of AIDS Research 11.3 (2012): 261-271.

19. Fair C and Albright J. “Don't tell him you have HIV unless he's 'the one'”: romantic relationships among adolescents with perinatal HIV infection". AIDS Patient Care STDs 26.12 (2012):746-754. 
20. Marques HH., et al. "[Disclosure of HIV infection from the perspective of adolescents living with HIV/AIDS and their parents and caregivers]". Cadernos de SaudePublica 21.41 (2013):176185.

21. Dusade-Richards E., et al. "Dealing with disclosure: Perspectives from HIV- positive children and their older carers living in rural south-western Uganda". African Journal of AIDS Research 15 (2016):387-395.

22. Mburu G., et al. "Adolescent HIV disclosure in Zambia: barriers, facilitators and outcomes". The Journal of the International AIDS Society 17 (2014):18866.

23. Patel K., et al. "Long term effectiveness of highly active antiretroviral therapy on the survival of children and adolescents with HIV infection : a 10 year follow-up study". Clinical Infectious Diseases 16 (2008):507-515.

24. Joint United Nations Programme on HIV/AIDS. Report on global HIV/AIDS epidemic: Joint United Nations Programme on HIV/AIDS (2008).

25. WHO, UNAIDS and UNICEF. GlobalHIV/AIDS response: epidemic update and health sector progress towards universal access. Progress report (2011).

26. Vreeman RC., et al. "The perceived impact of disclosure of pediatric HIV status on pediatric antiretroviral therapy adherence, child well being, and social relationships in resourcelimited setting". AIDS Patient Care STDs24 (2010): 639-649.

27. Eneh AU., et al. "HIV disclosure in children in a tertiary hospital in southern Nigeria-Child,s Perspective". AJMAH18.1 (2020):16-27.

28. Oyedeji GA. "Socio-economic and cultural background of hospitalized children in Ilesha". The Nigerian Journal of Paediatrics 12 (1985):111-117.

29. Cohen J., et al. "School-related issues among HIV -infected children”. Paediatrics100.1 (1997):2008-1290.

30. NACA. End of Term Desk Review Report of 2010-2015 National HIV/AIDS Strategic Plan (2015).
31. Blasini I., et al. "Disclosure model for paediatric patients living with HIV in Peurto Rico: Design, implementation and evaluation". Journal of Developmental and Behavioral Pediatrics 25.3 (2004): 181-189.

32. Battles HB and Weiner LS. "From adolescence through young adulthood: psychosocial adjustment associated with long-term survival of HIV". Journal of Adolescent Health 30.3 (2002):161168.

33. Fagbamigbe AF and Idemudia E. "Diversities in timing of sexual debut among Nigerian youths aged 15-24 years: parametric and non-parametric survival analysis approach". African Health Sciences 17.1 (2017):39-51.

\section{Assets from publication with us}

- Prompt Acknowledgement after receiving the article

- Thorough Double blinded peer review

- Rapid Publication

- Issue of Publication Certificate

- High visibility of your Published work

Website: www.actascientific.com/

Submit Article: www.actascientific.com/submission.php

Email us: editor@actascientific.com

Contact us: +919182824667 